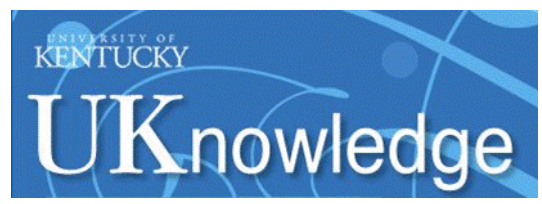

University of Kentucky

UKnowledge

$12-8-2020$

\title{
Dark Iron-Catalyzed Reactions in Acidic and Viscous Aerosol Systems Efficiently Form Secondary Brown Carbon
}

\author{
Hind A. Al-Abadleh \\ Wilfrid Laurier University, Canada \\ Md Sohel Rana \\ University of Kentucky, mdsohelrana@uky.edu \\ Wisam Mohammed \\ Wilfrid Laurier University, Canada \\ Marcelo I. Guzman \\ University of Kentucky, marcelo.guzman@uky.edu
}

Follow this and additional works at: https://uknowledge.uky.edu/chemistry_facpub

Part of the Chemistry Commons

Right click to open a feedback form in a new tab to let us know how this document benefits you.

\section{Repository Citation}

Al-Abadleh, Hind A.; Rana, Md Sohel; Mohammed, Wisam; and Guzman, Marcelo I., "Dark Iron-Catalyzed Reactions in Acidic and Viscous Aerosol Systems Efficiently Form Secondary Brown Carbon" (2020). Chemistry Faculty Publications. 191.

https://uknowledge.uky.edu/chemistry_facpub/191

This Article is brought to you for free and open access by the Chemistry at UKnowledge. It has been accepted for inclusion in Chemistry Faculty Publications by an authorized administrator of UKnowledge. For more information, please contact UKnowledge@lsv.uky.edu. 
Dark Iron-Catalyzed Reactions in Acidic and Viscous Aerosol Systems Efficiently Form Secondary Brown Carbon

Digital Object Identifier (DOI)

https://doi.org/10.1021/acs.est.0c05678

Notes/Citation Information

Published in Environmental Science \& Technology, v. 55, issue 1.

Copyright $\odot 2020$ American Chemical Society

This is an open access article published under a Creative Commons Non-Commercial No-Derivative Works (CC-BY-NC-ND) Attribution License, which permits copying and redistribution of the article, and creation of adaptations, all for non-commercial purposes.

This article is available at UKnowledge: https://uknowledge.uky.edu/chemistry_facpub/191 


\title{
Dark Iron-Catalyzed Reactions in Acidic and Viscous Aerosol Systems Efficiently Form Secondary Brown Carbon
}

\author{
Hind A. Al-Abadleh,* Md Sohel Rana, Wisam Mohammed, and Marcelo I. Guzman*
}

Cite This: Environ. Sci. Technol. 2021, 55, 209-219

Read Online

ABSTRACT: Iron-driven secondary brown carbon formation reactions from water-soluble organics in cloud droplets and aerosols create insoluble and soluble products of emerging atmospheric importance. This work shows, for the first time, results on dark iron-catalyzed polymerization of catechol forming insoluble black polycatechol particles and colored water-soluble oligomers under conditions characteristic of viscous multicomponent aerosol systems with relatively high ionic strength $(I=1-12 \mathrm{~m})$ and acidic $\mathrm{pH}(\sim 2)$. These systems contain ammonium sulfate (AS)/nitrate (AN) and C3-C5 dicarboxylic acids, namely, malonic, malic, succinic, and glutaric acids. Using dynamic light scattering (DLS) and ultra high pressure liquid chromatography-mass spectrometry (UHPLC-MS), we show results on the rate of

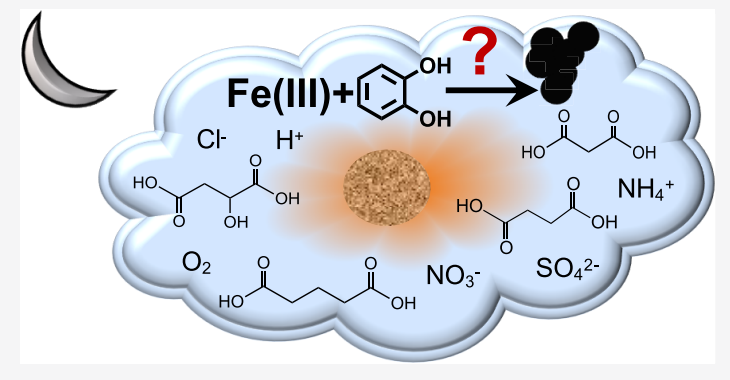
particle growth/agglomeration and identity of soluble oligomeric reaction products. We found that increasing $I$ above $1 \mathrm{~m}$ and adding diacids with oxygen-to-carbon molar ratio $(\mathrm{O}: \mathrm{C}>1)$ significantly reduced the rate of polycatechol formation/aggregation by a factor of $1.3 \pm 0.4$ in AS solution in the first $60 \mathrm{~min}$ of reaction time. Using AN, rates were too slow to be quantified using DLS, but particles formed after $24 \mathrm{~h}$ reaction time. These results were explained by the relative concentration and affinity of ligands to $\mathrm{Fe}(\mathrm{III})$. We also report detectable amounts of soluble and colored oligomers in reactions with a slow rate of polycatechol formation, including organonitrogen compounds. These results highlight that brown carbon formation from iron chemistry is efficient under a wide range of aerosol physical states and chemical composition.

\section{INTRODUCTION}

Processes that lead to secondary organic aerosol (SOA) formation include atmospheric oxidation of volatile organic compounds (VOCs) from biogenic and anthropogenic sources, gas-particle partitioning, and multiphase/heterogenous reactions. ${ }^{1-4}$ Also, a number of chemical and photochemical aging processes of primary aerosols and SOA lead to the formation of "brown carbon", a term that refers to lightabsorbing soluble and insoluble components. ${ }^{5}$ The role of transition metals such as iron in the formation and aging of SOA is not well understood. ${ }^{6}$ Iron is a ubiquitous component of mineral dust, fly ash, and marine aerosols with speciation that varies by aerosol source. ${ }^{7-12}$ The fraction of soluble iron in particles is enhanced via uptake of acidic gases during longrange transport. ${ }^{11,13,14}$ Cycling between wet aerosols and cloud droplets not only changes the $\mathrm{pH}$ from highly acidic to more neutral values but also affects the concentration of soluble iron. ${ }^{15}$ The soluble iron content can drive reactions that change the optical properties of dust to be more light absorbing at all wavelengths, as we recently shown from the reaction of Arizona Test Dust and hematite nanoparticles with catechol as a function of $\mathrm{pH} .^{16}$

A number of (photo)chemical reactions in atmospheric cloud droplets and aerosols are catalyzed by soluble iron, forming either soluble or insoluble products. For example, redox cycling between $\mathrm{Fe}(\mathrm{II})$ and $\mathrm{Fe}(\mathrm{III})$ species has been shown to catalyze S(IV) oxidation and production of hydroxyl and organic peroxy radicals. ${ }^{6,12,17,18}$ Another example of redox reactions catalyzed by $\mathrm{Fe}$ (III) is the formation of soluble organosulfates from the reaction of $\mathrm{C} 2-\mathrm{C} 4$ unsaturated carbonyl compounds methacrolein (MACR) and methyl vinyl ketone (MVK) with bisulfite anion. ${ }^{19}$ On the other hand, aqueous phase reactions of $\mathrm{Fe}$ (III) with soluble aromatic compounds detected in biomass burning aerosols and unsaturated C4-C6 dicarboxylic acids detected in aged secondary organic aerosols lead to efficient formation of insoluble and colored polymeric compounds, even in the presence of competing ligands such as sulfate and oxalate. ${ }^{20-22}$

A number of factors affect the rate of reactions in atmospheric cloud/fog droplets and deliquescent aerosol systems containing $\mathrm{Fe}(\mathrm{II}) / \mathrm{Fe}$ (III) species. These factors include the concentration of reactants, $\mathrm{pH}$, and ionic strength (I), which are chiefly dependent on the aerosol liquid water content (ALW). The amount of ALW in atmospheric particles

Received: August 25, 2020

Revised: November 20, 2020

Accepted: November 25, 2020

Published: December 8, 2020

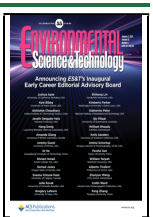


Table 1. Chemical Composition and Physical Properties of Background Solutions for the Reaction between Iron Chloride and Catechol Using Ammonium Sulfate (AS) as Salt

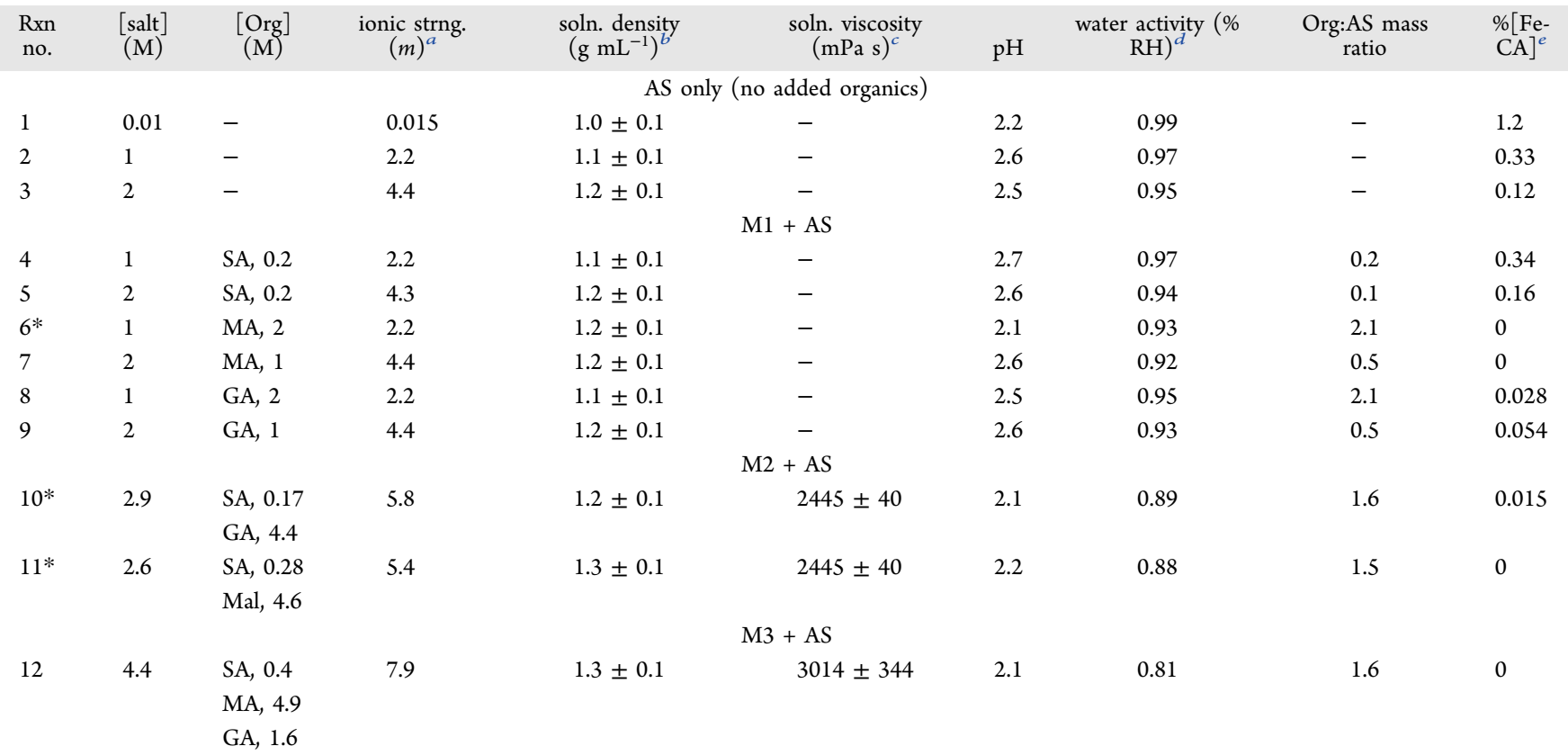

${ }^{a}$ Calculated using $I=1 / 2 \sum_{1}^{i} C_{i} z_{i}^{2}$, where $C_{i}$ is the concentration of charged species in solution in molality $(m)$ calculated using Visual MINTEQ ${ }^{39}$ for each solution. "Calculated from the mass of a known volume. "Measured in this study using a viscometer for low viscosity fluids. The "-" indicates the instrument was not accurately measuring viscosity using water-like fluids around $1 \mathrm{mPa}$ s. ${ }^{d} \mathrm{Calculated}$ using E-AIM, Model IV, Aqueous solutions. ${ }^{e}$ Calculated using Visual MINTEQ for each solution relative to total Fe(III) aqueous species in solution. Abbreviations are: Rxn = reaction, $\mathrm{AS}=$ ammonium sulfate, Org = organic compound, $\mathrm{SA}=$ succinic acid, $\mathrm{MA}=$ malic acid, GA = glutaric acid, and $\mathrm{Mal}=$ malonic acid. M1-3 refers to the number of the organic compounds in the solution per the terminology used by Marcolli et al. ${ }^{40}$ The concentrations are in the final solutions after mixing. All solutions contained final concentrations of $2 \times 10^{-3}$ and $1 \times 10^{-3} \mathrm{M}$ of Fe(III) and catechol, respectively. The final solution volume of Rxn no. 1-8 was $20 \mathrm{~mL}$ and Rxn no. 9-11 was $5 \mathrm{~mL}$. The '*' marks the reactions that were analyzed using UHPLC-UV-MS after filtration. See the text for details.

is a function of temperature, relative humidity $(\mathrm{RH})$, and chemical composition (inorganic vs organic). ${ }^{23,24}$ The aqueous phase volume in cloud/fog droplets is about $10^{-1} \mathrm{~cm}^{3} \mathrm{~m}^{-3}$ with $\mathrm{pH}$ values range $2-7$ and $I$ of $10^{-4} \mathrm{M}$, compared to $\sim 10^{-6}$ $\mathrm{cm}^{3} \mathrm{~m}^{-3}$ in deliquescent aerosols with $\mathrm{pH}$ values below 2 and $I$ $>6 \mathrm{M}$ depending on the source location (e.g., marine, urban, continental). ${ }^{25}$ These values are largely controlled by the inorganic salt content of atmospheric droplets/aerosols. Nonmarine inorganic salts are dominated by sulfate and nitrate from the oxidation of $\mathrm{SO}_{2}$ and $\mathrm{NO}_{x}$, respectively, rendering these particles acidic. ${ }^{26,27}$ Neutralization reactions due to ammonia gas uptake increase the concentration of ammonium in particles. ${ }^{26,27}$ The organic content in atmospheric particles is characterized by a number of functional groups that range in the oxygen-to-carbon elemental ratio (O:C) from 0.1 to $1.0 .^{28}$ Uptake of VOCs from biogenic and anthropogenic sources, gas and particle phase oxidation reactions can produce low-volatility products leading to mixing of organic species with inorganic salts. ${ }^{28}$ As a result, the morphology and mixing state in the systems that can undergo deliquescence, efflorescence, and liquid-liquid phase separation are directly dependent on ALW. ${ }^{29-31}$ Moreover, lab and model studies on primary and secondary organic aerosols show that temperature, $\mathrm{RH}$, and molecular composition affect the size, viscosity, and phase state of these aerosols, which in turn affect the relative importance of bulk versus surface reactions. ${ }^{32-34}$

The objective of this study is to investigate the extent of iron-catalyzed polymerization of catechol under conditions characteristic of relatively viscous multicomponent aerosol systems and adsorbed water ${ }^{20}$ with high ionic strength $(I=1-$ $12 \mathrm{~m})$, acidic $\mathrm{pH}(\sim 2),{ }^{23,25,35}$ and low water activity $(0.6-$ $0.97) .^{36}$ This reaction was chosen because our earlier studies were completed under conditions typical of cloud chemistry ( $I$

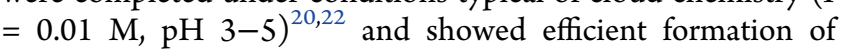
polycatechol, a black agglomerate of soot-like particles that we named "fireless soot". In this study, acidic multicomponent background aqueous phase solutions were prepared by adding either ammonium sulfate (AS) or ammonium nitrate (AN), and ubiquitous $\mathrm{C} 3-\mathrm{C5}$ dicarboxylic acids (malonic, malic, succinic, and glutaric acids) detected in biomass burning aerosols ${ }^{37}$ and used in laboratory studies investigating liquidliquid phase separation. ${ }^{28}$ The relative amounts of the organic (Org) and inorganic (Inorg) components were varied to achieve mass ratios reported for field aerosols, Org:Inorg = $0.2-3.5^{28}$ These salts and diacids did not only influence the $\mathrm{pH}$, I, water activity, and viscosity of the solutions but also competed for binding to iron, specifically the anionic species. ${ }^{38}$ The main hypothesis being tested in this study is whether salts and diacids suppress the formation of polycatechol because of soluble iron complexes.

\section{MATERIALS AND METHODS}

Chemicals. All chemicals were used as received without further purification. More details on the sources, purity, physical properties of the organic acids, and description of solution preparation are provided in the Supporting Information (SI) and Table S1. 


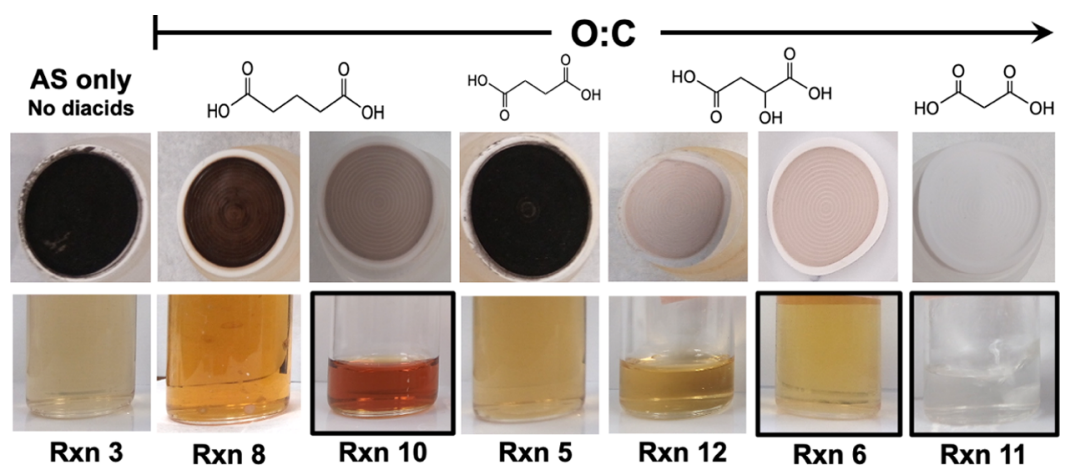

Figure 1. Digital photographs of filters and filtrate solutions after $24 \mathrm{~h}$ of selected reactions listed in Table 1 between catechol $\left(1 \times 10^{-3} \mathrm{M}\right)$ and $\mathrm{FeCl}_{3}\left(2 \times 10^{-3} \mathrm{M}\right)$ in AS solutions. The photographs are arranged in order of the increasing O:C molar ratio of the most dominant diacids based on the structures shown. The black border marks the filtrate samples analyzed using UHPLC-UV-MS and ion chromatography MS. The corresponding photographs for the control reactions in the absence of catechol are shown in Figure S2.

Aqueous Phase Experiments. The composition of the background solutions is shown in Tables 1 and S2 using ammonium sulfate (AS) and ammonium nitrate (AN), respectively.

The concentration of the diacids ranged from 0.4 to $5 \mathrm{M}$, AS from 0.01 to $4 \mathrm{M}$, and AN from 0.01 to $12.3 \mathrm{M}$ to modify the $I$, Org:Inorg mass ratio, and water activity of the reaction solutions. These concentrations are atmospherically relevant as they mimic the high solute:solvent ratio in adsorbed water and in aerosols with relatively low ALW. ${ }^{25}$ Solution density and viscosity were measured in the lab by weighing a known volume and using a viscometer (IKA ROTAVISC LO-VI with a VOLS-1 accessory), respectively. The final concentrations of catechol and $\mathrm{Fe}$ (III) were $1 \times 10^{-3}$ and $2 \times 10^{-3} \mathrm{M}$, three orders of magnitude less than those of the dicarboxylic acids, AS and AN. All reactions were run under dark conditions. More details are provided in the Supporting Information (SI).

Dynamic Light Scattering Experiments. DLS experiments were performed to monitor the growth of insoluble polymeric materials forming in solution within the first hour of reaction time. The reaction took place in a $20 \mathrm{~mL}$ vial containing $10 \mathrm{~mL}$ of a given background solution per Tables 1 and $\mathrm{S} 2$ in addition to catechol at $1 \times 10^{-3} \mathrm{M}$. The timer started with the addition of $0.1 \mathrm{~mL}$ of $\mathrm{FeCl}_{3}$ to result in a final concentration of $2 \times 10^{-3} \mathrm{M}$. Within the first minute of reaction, $3 \mathrm{~mL}$ were taken to the $1 \mathrm{~cm}$ disposable cuvette located in the DLS instrument, Malvern Zetasizer Nano (ZEN3600), to start the data collection. More details are provided in the Supporting Information (SI).

Chromatography Analyses. Selected filtrate samples were chosen for identifying the soluble products responsible for the observed color shown in Figure 1. These samples were diluted 100 times and analyzed by UHPLC-UV-MS (Accela 1250 with tandem photodiode array and MSQ Plus detectors, Thermo Scientific) ${ }^{41}$ equipped with a C18 column (ZORBAX Eclipse Plus RR HD, $2.1 \mathrm{~mm} \times 100 \mathrm{~mm}, 1.8 \mu \mathrm{m})$. An electrospray ionization (ESI) source served as the interface between the UHPLC and MS. Four solvents were used to create gradients in a 16 min program at a flow rate of $0.400 \mathrm{~mL}$ $\min ^{-1}$, with $5 \times 10^{-3} \mathrm{M}$ formic acid in water (solvent A) or acetonitrile (solvent B) for $\operatorname{ESI}(-) / \mathrm{MS}$ and $1 \times 10^{-3} \mathrm{M}$ ammonium formate in water (solvent $C$ ) or acetonitrile (solvent D) for ESI(+)/MS. Samples for Rxn 10 were also analyzed using high resolution-mass spectrometry (HR-MS, positive mode) with a quadrupole orbitrap. More details are provided in the Supporting Information (SI).

\section{RESULTS AND DISCUSSION}

Correlation of the $\mathrm{O}: \mathrm{C}$ Ratio With Insoluble and Soluble Product Formation. Iron-catalyzed oxidative polymerization of catechol was studied in variable background solutions, as shown in Tables 1 and S2 to model aerosol systems under acidic conditions. The concentration of chemicals was chosen to achieve the Org:Inorg (AS or AN) mass ratio between 0.5 and 2 . This mass ratio range was measured in field-collected organic aerosols from the pristine Amazon Basin ${ }^{42}$ and many locations in the Northern Hemisphere. ${ }^{43,44}$ The diacids chosen for this study have an $\mathrm{O}: \mathrm{C}$ molar ratio greater than or equal to 0.8 . Previous work on aerosol systems containing organics with this molar ratio range showed no liquid-liquid phase separation as a function of the Org:AS mass ratio range used here. ${ }^{45}$ Instead, deliquescence (D) and efflorescence (E) were observed in these systems with $\mathrm{DRH}$ and ERH ranging from 45 to 80 and 10 to $35 \%$, respectively. ${ }^{45}$ The calculated water activity in the solutions in Tables 1 and S2 ranges from 0.6 to 0.99 , hence covering a relatively wide range of ALW.

Figures 1 and S1 show digital photos of particles on filters and filtrate solutions from the reaction of catechol with $\mathrm{Fe}$ (III) as a function of the O:C molar ratio in the background solutions listed in Table 1. For comparison, images for the control reactions in Figure 1 in the absence of catechol are shown in Figure S2. These qualitative results clearly show that the insoluble black particles and brownish soluble reaction products in Figures 1 and S1 originated from catechol. Also, the type of the diacid and its concentration relative to AS in the background solutions affected the particle density after 24 $\mathrm{h}$ reaction time as inferred from the color of the filters. This is because these diacids and AS can complex Fe(III) and hence compete with catechol. ${ }^{38}$ In the $\mathrm{pH}$ range $2-2.5$, the dominant iron species are $\mathrm{Fe}^{3+}$ and $\mathrm{FeOH}^{2+}$. ${ }^{2}$ Table $\mathrm{S} 3$ lists values for the forward complex formation rate constants, $k_{\mathrm{f}}$, between $\mathrm{FeOH}^{2+}$ and selected ligands of direct relevance to our study. Although the experimental conditions in Table S3 do not represent the ones in this study, the $k_{\mathrm{f}}$ value for forming the iron catecholate complex, $\mathrm{Fe}\left(\mathrm{C}_{6} \mathrm{O}_{2} \mathrm{H}_{4}\right)^{+}(\mathrm{Fe}-\mathrm{CA})$, is $3 \times$ that for forming iron sulfate, $\mathrm{Fe}\left(\mathrm{SO}_{4}\right)_{2}{ }^{-}$, and iron malate, $\mathrm{Fe}\left(\mathrm{C}_{4} \mathrm{O}_{5} \mathrm{H}_{4}\right)^{+}(\mathrm{Fe}-\mathrm{MA})$. Because of the sparsity of reliable kinetic studies on iron complex formation with the rest of the ligands used here, 
Table 2. Dominant Iron Species at Equilibrium as Calculated Using Visual MINTEQ for Each Reaction Solution Listed in Table 1 With Ammonium Sulfate (AS) ${ }^{a}$

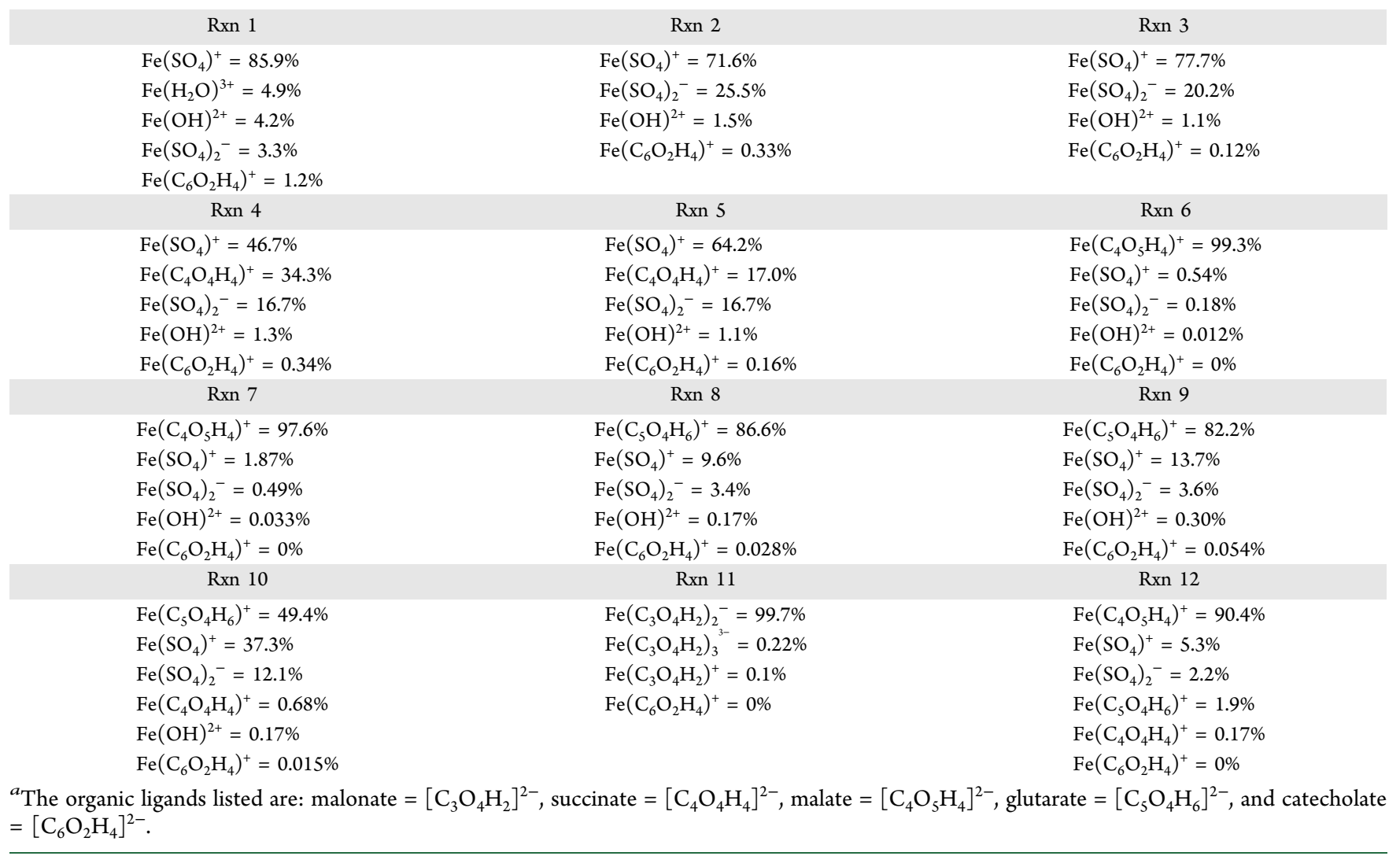

interpretation of the results will be based on the values of the thermodynamic stability constants $(\log K)$ for these complexes, as listed in the Supporting Information, S1-S40. In the presence of excess dissolved iron and dissolved oxygen, iron catalyzes the deprotonation of catechol below its first $\mathrm{p} K_{\mathrm{a}}{ }^{46}$ The $\log K$ value for the formation of Fe-CA per eqs 1 and 2 is 7.9 and 9.9 depending on the iron species

$$
\begin{aligned}
& (\mathrm{S} 15)+(\mathrm{S} 27) \mathrm{Fe}^{3+}+\mathrm{H}\left(\mathrm{C}_{6} \mathrm{O}_{2} \mathrm{H}_{4}\right)^{-} \rightleftharpoons \mathrm{Fe}\left(\mathrm{C}_{6} \mathrm{O}_{2} \mathrm{H}_{4}\right)^{+} \\
& \quad+\mathrm{H}^{+} \\
& (\mathrm{S} 15)-(\mathrm{S} 16)+(\mathrm{S} 27) \\
& \mathrm{FeOH}^{2+}+\mathrm{H}\left(\mathrm{C}_{6} \mathrm{O}_{2} \mathrm{H}_{4}\right)^{-} \rightleftharpoons \mathrm{Fe}\left(\mathrm{C}_{6} \mathrm{O}_{2} \mathrm{H}_{4}\right)^{+}+\mathrm{H}_{2} \mathrm{O}
\end{aligned}
$$

These $\log K$ values are the highest compared to those of the diacids as listed in Supporting Information reactions S28-S40. Iron complexes with the diacids are stable in the aqueous phase, whereas Fe-CA complexes get oxidized and polymerized under acidic conditions (see the mechanism in the Supporting Information in reference, ${ }^{22}$ which is also described below). Hence, quantifying iron species in solution using thermodynamic models would aid in interpreting the results, particularly because iron is the limiting reagent and the concentration of the diacids is nearly $1000 \times$ higher than that of catechol in the reaction. The dominant iron species relative to total iron in solution are listed in Table 2, which were calculated using the Visual MINTEQ software for each reaction solution in Table 1. The formation of Fe-CA complexes is the first step in the oxidative polymerization reaction that leads to the formation of insoluble polycatechol. ${ }^{20}$ In solutions with AS only, the \%Fe-
CA ranged from 1.2 to 0.12 with increasing AS concentration $(\mathrm{Rxn} 1-3)$. The addition of succinic acid (SA, O:C = 1) in $\mathrm{Rxn} 4$ and 5 decreased the fraction of iron sulfate $\left(\mathrm{Fe}\left(\mathrm{SO}_{4}\right)^{+}\right.$ and $\left.\mathrm{Fe}\left(\mathrm{SO}_{4}\right)_{2}{ }^{-}\right)$compared with $\mathrm{Rxn} 2$ and 3 due to the formation of iron succinate species $\left(\mathrm{Fe}\left(\mathrm{C}_{4} \mathrm{O}_{4} \mathrm{H}_{4}\right)^{+}\right)$. The \%Fe$\mathrm{CA}$ in these solutions was similar to those in $\mathrm{Rxn} 2$ and 3 with no SA. This result is due to the complexation affinity of catechol being higher than SA to Fe(III). In Rxn 6 and 7, malic acid (MA, O:C $=1.25$ ) was added, which significantly decreased the $\% \mathrm{Fe}\left(\mathrm{SO}_{4}\right)^{+}$and $\mathrm{Fe}\left(\mathrm{SO}_{4}\right)_{2}{ }^{-}$species compared with Rxn 2 and 3 and completely suppressed the formation of Fe-CA species. On the other hand, the presence of glutaric acid $(\mathrm{Rxn} 8,9)$ reduced the formation of $\mathrm{Fe}\left(\mathrm{SO}_{4}\right)^{+}$and $\mathrm{Fe}\left(\mathrm{SO}_{4}\right)_{2}{ }^{-}$ to a lesser extent than MA in Rxn 6 and 7. The \%Fe-CA in Rxn 8 and 9 is 0.028 and $0.054 \%$, nearly $10 \times$ less than that with SA at (Rxn 4 and 5), but nonzero as observed with MA. These results are clearly in line with the $\log K$ values of $\mathrm{Fe}(\mathrm{III})$ complexes with GA being between the $\log K$ values of $\mathrm{Fe}(\mathrm{III})$ with MA and those with SA (see eqs S39 and S40 for GA versus S35, S36 for MA and S37 and S38 for SA).

The background AS solutions in Rxn 10 and 11 contained two added diacids (M2 + AS, Table 1), which were SA and GA (Rxn 10) and SA and Mal (Rxn 11). The concentrations of these components resulted in higher solution density and lower water activity than the M1 + AS solutions, Rxn 1-9. As inferred from the speciation trends in Rxn 1-9 discussed above, mixing SA with GA in Rxn 10 resulted in the formation of predominantly iron glutarate $\left(\mathrm{Fe}\left(\mathrm{C}_{5} \mathrm{O}_{4} \mathrm{H}_{6}\right)^{+}\right)$complexes followed by iron sulfate species $\left(\mathrm{Fe}\left(\mathrm{SO}_{4}\right)^{+}\right.$and $\left.\mathrm{Fe}\left(\mathrm{SO}_{4}\right)_{2}{ }^{-}\right)$ then iron succinate $\left(\mathrm{Fe}\left(\mathrm{C}_{4} \mathrm{O}_{4} \mathrm{H}_{4}\right)^{+}\right)$. This trend followed the concentrations of the corresponding ligands in solution (i.e, AS, GA, and SA). The \%Fe-CA species was 0.015 , much lower 


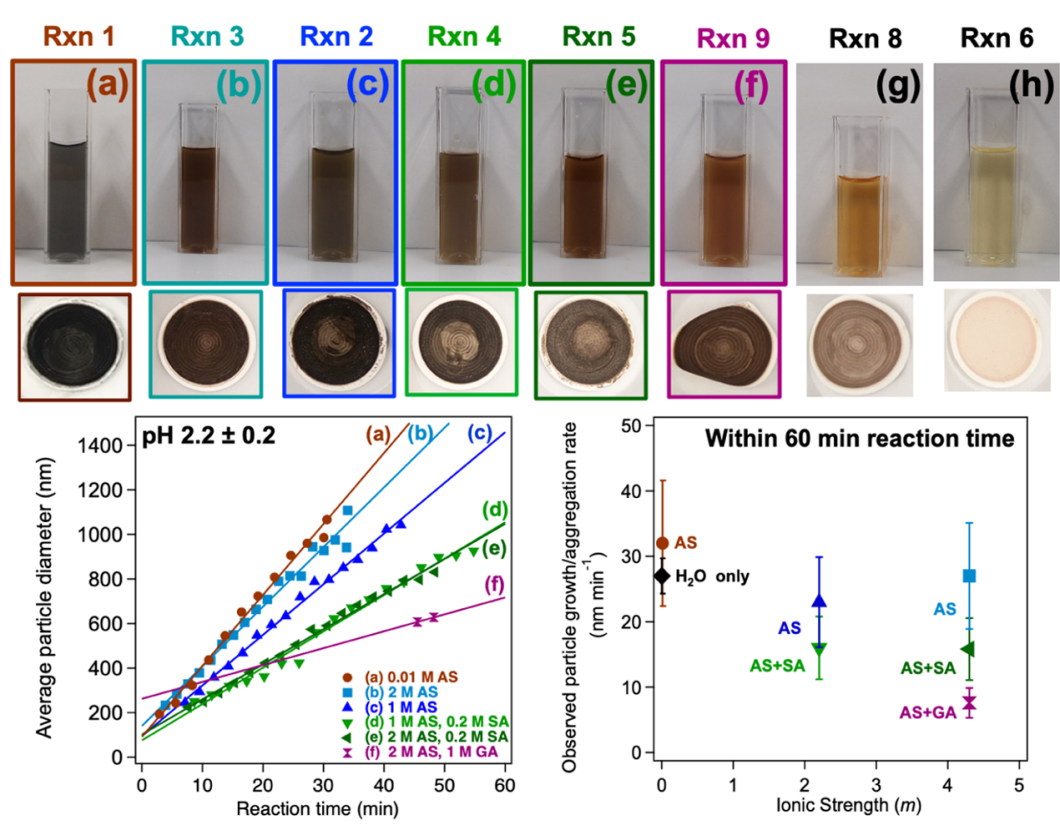

Figure 2. Top panel: vials containing suspensions of polycatechol particles after 60 min reaction between catechol $\left(1 \times 10^{-3} \mathrm{M}\right)$ and $\mathrm{FeCl}_{3}(2 \times$ $\left.10^{-3} \mathrm{M}\right)$ in AS solutions using DLS in different background solutions listed in Table 1: Vials in a-h are arranged in the order of the decreasing rate of particle formation/agglomeration. Middle panel: filters of particles after $24 \mathrm{~h}$ reaction time in the samples shown in the top panel. Bottom panel: (Left) DLS measurements of the average particle size of polycatechol as a function of time $( \pm 1 \sigma=30 \%$, error bars were removed for clarity). Lines through the data correspond to linear least-squares fitting. (Right) The observed rate of particle growth or aggregation as a function of ionic strength from the DLS data with error bars represents $\pm 1 \sigma$.

than those calculated for Rxn 4, 5, 8, and 9. In Rxn 11 with malonic acid (Mal, O:C = 1.33), the dominant species were the iron malonate complexes in the bi- $>$ tri- $>$ monodentate configurations (Table 2). The ability of Mal to form more than one type of iron complex is similar to that of oxalic acid (O:C $=2)^{2,47} \mathrm{We}$ previously showed that excess oxalic acid suppressed the formation of polycatechol under cloud chemistry conditions due to the formation of soluble iron oxalate complexes with multiple coordination. ${ }^{22}$ So, because $\mathrm{Fe}$ (III) was almost completely complexed with malonate, no polycatechol particles were formed, as observed qualitatively in Figure 1.

The background AS solution in Rxn 12 contained three diacids, SA, MA, and GA (M3 + AS, Table 1). While this solution had the same density as Rxn 10 and 11, the calculated water activity was lower (0.81 compared to 0.89 and 0.88 , respectively). Since the concentration of MA was the highest, iron malate species $\left(\mathrm{Fe}\left(\mathrm{C}_{4} \mathrm{O}_{5} \mathrm{H}_{4}\right)^{+}\right)$were the dominant iron complexes, followed by iron sulfate, iron glutarate, and iron succinate. This trend followed the concentrations of the corresponding ligands in solution (i.e, MA > AS > GA > SA). As a result, the formation of the aforementioned complexes drastically reduced polycatechol formation (Figure 1).

As discussed above for Table 1 , despite the very low values of \% Fe-CA in Rxn 2-12, polycatechol particles still formed (as judged by the color of the filters for reaction and control experiments) with an apparent reduction in particle density with increasing concentrations of the diacids that strongly complex to iron ( $\mathrm{Mal}>\mathrm{MA}>\mathrm{GA})$. This trend correlated with the O:C molar ratio of these diacids (Table S1: $1.33>1.25>$ 0.8 , respectively). SA was removed from this list because it had lower solubility than the other diacids, which prevented our ability to conduct experiments using concentrations at 1 and 2 $\mathrm{M}$. The case of $\mathrm{Rxn} 11$ where Mal is the dominant diacid was the only one where no evidence of particle formation was observed. For Rxn 6, 7, and 12, the Visual MINTEQ thermodynamic model calculated a \%Fe-CA to be zero, yet discoloration of filters was apparent after $24 \mathrm{~h}$ reaction (Figure 1 ). This discoloration is due to traces of polycatechol particles suggesting a significant reduction in the rate of particle growth under these reaction conditions.

For comparison with AS, selected experiments using AN were also conducted under the same conditions. Table $S 2$ lists Rxn 1-10 using AN only, AN with the addition of one type of diacid $(\mathrm{M} 1+\mathrm{AN})$, and with three types of diacids $(\mathrm{M} 3+\mathrm{AN})$. Nitrate is a much weaker ligand than sulfate, hydroxide, and chloride, ${ }^{48}$ and hence the calculated fraction of iron species in solution did not contain iron nitrate, as shown in Table S4. For Rxn $1^{\prime}-4^{\prime}$ with no diacids, increasing the concentration of AN from 0.01 to $12.3 \mathrm{M}$ reduced the \%Fe-CA from 9.5 to 2.4 . The $\% \mathrm{Fe}-\mathrm{CA}$ in AN solutions were considerably higher than those for Rxn 1-3 using AS, which ranged from 1.2 to 0.12 (Table $2)$. As will be shown in the next section, this difference will have implications on the rate of particle growth/agglomeration determined in DLS experiments. The addition of the diacids to the AN solutions had a larger impact on the \%Fe-CA than increasing AN concentration. For example, Rxn $2^{\prime}, 5^{\prime}$, and $7^{\prime}$ contained AN at $1 \mathrm{M}$, with $0.2 \mathrm{M} \mathrm{SA}$ in Rxn $5^{\prime}$ and $2 \mathrm{M}$ GA in Rxn $7^{\prime}$. The \%Fe-CA dropped from 4.0 to 0.8 and 0.03 , respectively. This is because SA and GA formed stable iron complexes per reactions $S 37-S 40$ in the Supporting Information. And since the concentration of SA is 200-times higher $\left(\operatorname{Rnx} 5^{\prime}, 6^{\prime}\right)$ and GA 2000- and 1000-times (Rnx 7', 8') higher than the concentration of catechol, they significantly reduced the amount of iron available for complexation. Figure $\mathrm{S} 3 \mathrm{~b}, \mathrm{~d}$, f shows digital photos for $\mathrm{Rxn} 2^{\prime}, 5^{\prime}$, and $7^{\prime}$ after $60 \mathrm{~min}$ reaction and the corresponding filters following overnight reaction. There is a noticeable qualitative difference between Figure S3b,d, compared with Figure S3f, where lighter color was apparent for the reaction solution and filter. This result 
was expected since the concentration of GA in Rxn $7^{\prime}$ (Figure S3d) is $10 \times$ that of SA in Rxn 5' (Figure S3b) and confirmed the concentration dependence interpretation mentioned above for $\% \mathrm{Fe}-\mathrm{CA}$. Similar qualitative observations could be made when comparing Rxn $3^{\prime}, 6^{\prime}$, and $8^{\prime}$ (Figure S3c,e,g) that contained $\mathrm{AN}$ at $2 \mathrm{M}$. These observations suggest that increasing AN concentration had no apparent effect on particle density. Figure S3g for Rxn $8^{\prime}$ shows the reaction solution that contained half the concentration of GA in Rxn $7^{\prime}$ (Figure S3f), which resulted in relatively higher $\% \mathrm{Fe}-\mathrm{CA}$ at 0.07 for Rxn $8^{\prime}$. Hence, the visibly darker filter from Rxn $8^{\prime}$ suggests more polycatechol formation than from Rxn $7^{\prime}$. In summary, ironcatalyzed polycatechol formation in multicomponent background solutions is a kinetically controlled process that (a) does not only depend on the concentration of the inorganic salt used to adjust $I$ but also the type of the anion in that salt and its affinity for complexation to iron and (b) is affected by the concentration and the number of complexes organic diacids form with iron.

Kinetics of Polycatechol Particle Growth/Agglomeration. To investigate the kinetics of particle growth due to polycatechol formation, DLS experiments were conducted in selected AS and AN background solutions (Rxn 1-6, 8, and 9 in Table 1 and Rxn $1^{\prime}-8^{\prime}$ in Table S2, respectively). In these measurements, the hydrodynamic average size of particles $(\langle d\rangle)$ formed in solution was monitored as a function of reaction time within the first $60 \mathrm{~min}$. Figures 2 and S3 summarize the results from these experiments. The top panel shows digital images of the vials containing suspensions of the polycatechol particles at the end of the DLS measurements arranged in the order of the decreasing particle growth/ agglomeration rate (from left to right). The solutions in the reaction vials were filtered after $24 \mathrm{~h}$ and dried overnight (middle panel of Figures 2 and S3).

Qualitative inspection of the slurries containing polycatechol in the top panel of Figure 2 after 60 min reaction time showed that there was a visible decrease in the intensity of the color that correlated with the presence of the diacids, SA, GA, and MA in $d-h$. The time dependence of $\langle d\rangle$ is shown in the lower left plot of Figure 2. As stated in the Methods section in the Supporting Information, only $<d>$ with PDI $<0.4$ and a mean count rate greater than $100 \mathrm{kcps}$ were selected for the rate derivation. A linear least-squares fitting was used to obtain the observed initial rates of particle growth/agglomeration from the experimental data. The slopes from the best fits were then plotted as a function of $I$ of the background solutions (lower right plot in Figure 2). Within the uncertainty of the measurement, these data showed that increasing $I$ and adding diacids reduced the initial rate of polycatechol growth/ agglomeration. Specifically, reactions in background solutions having $I=2.2$ and $4.4 \mathrm{~m}$ AS only are slower by nearly a factor of $1.3 \pm 0.4$ compared to $10^{-2} \mathrm{~m}$ AS (Rxn 2 and 3 vs Rxn 1 ). This result could be explained by the reduction in $\% \mathrm{Fe}-\mathrm{CA}$ with increasing concentration of AS from 1.2 to 0.33 to 0.12 (Rxn 1-3, Table 2). The addition of SA at concentrations nearly $10 \times$ lower than AS decreased the rate of polycatechol growth/agglomeration relative to AS only at the same molality by a factor $\sim 1.6 \pm 0.5(\operatorname{Rxn} 4,5$, Table 2$)$. These solutions with SA had similar \%Fe-CA to those containing AS only (0.34 and 0.16 ). This result could be explained by the formation of iron succinate complexes, $\mathrm{Fe}\left(\mathrm{C}_{4} \mathrm{O}_{4} \mathrm{H}_{4}\right)^{+}$, at the expense of iron sulfate, as shown in Table 2. The $\mathrm{Fe}\left(\mathrm{C}_{4} \mathrm{O}_{4} \mathrm{H}_{4}\right)^{+}$complexes are larger in size than iron sulfate and their formation in solution increased the percentage of positively charged species compared to AS only (Rxn 2, 3). These species might have interfered with the particle growth mechanism where positively charged Fe-CA formed in the initial steps. Polycatechol formation in solution falls under the category of "mechanisms for polymerization reactions". Free radical polymerization reactions are composed of three main steps: initiation, propagation, and termination. ${ }^{49}$ Hence, steric and electrostatic factors might have played a role in decreasing the rate of polycatechol growth/agglomeration upon adding SA. The addition of MA in Rxn 6 (and 7) did not produce polycatechol over $60 \mathrm{~min}$ reaction time during the DLS experiments and hence yielded unreliable values for $\langle d\rangle$. The calculated $\% \mathrm{Fe}-$ $\mathrm{CA}$ in these reactions were 0 as soluble iron malate, $\mathrm{Fe}\left(\mathrm{C}_{4} \mathrm{O}_{5} \mathrm{H}_{4}\right)^{+}$, dominated iron species in solution at 99.3 and 97.6\%. Interestingly, analysis of filtrate samples for Rxn 6 shows the presence of soluble oligomers responsible for the yellow color, as described in the next section.

Moreover, the addition of 1 and $2 \mathrm{M}$ GA to AS at $I=2.2$ and $4.4 m$ per Rxn 8 and 9, respectively, decreased the initial rate of polycatechol growth/agglomeration to a larger extent than SA. Values of $\langle d\rangle$ collected for Rxn 8 over the $60 \mathrm{~min}$ reaction time were unreliable as they did not meet the criteria outlined in the Experimental Section. Particles collected on the filter after allowing the reaction to proceed for $24 \mathrm{~h}$ showed a relatively lower density of particles than other reactions. The $\%$ $\mathrm{Fe}-\mathrm{CA}$ in this reaction was 0.028 . This result suggested a relatively much slower initial rate of particle growth/ agglomeration to be detected in real time using DLS relative to $\mathrm{Rxn} 1-5$. The observed initial rate of polycatechol growth/ agglomeration in Rxn 9 was lower by nearly a factor of $4 \pm 1$ relative to AS only at the same $I(\operatorname{Rxn} 3)$. The $\langle d\rangle$ data points for Rxn 9 shown in lower left panel Figure 2 were the only ones that fit the criteria described in the Experimental Section. A number of factors might have contributed to this initial rate reduction that include the relatively very small concentration of $\% \mathrm{Fe}-\mathrm{CA}$ complexes in solution at 0.054 and the dominance of the bulky and positively charged iron glutarate complexes $\mathrm{Fe}\left(\mathrm{C}_{5} \mathrm{O}_{4} \mathrm{H}_{6}\right)^{+}(82 \%)$ that interfered with the particle growth mechanism. In summary, within the uncertainty of the DLS measurements, increasing $I$ with AS (by a factor 200-400) did not significantly influence the initial rate of $\mathrm{Fe}(\mathrm{III})$-catalyzed polycatechol growth/agglomeration. Adding diacids, however, with an O:C molar ratio 0.8 and 1 (GA and SA, respectively) resulted in a statistically significant reduction in the initial rate by nearly factor of 2 for low concentrations $(0.2 \mathrm{M})$ and by a factor of 4 for high concentrations $(2 \mathrm{M})$. The initial rate of polycatechol growth/agglomeration was fully suppressed upon adding diacids with an O:C molar ratio greater than 1. Figures S3 and S4 show the DLS results on polycatechol growth/ agglomeration in AN solutions (a-e, Rxn 1'-3', 5', 6'). A detailed analysis of these DLS results is provided in the Supporting Information. In summary, the DLS results using AS and AN strongly suggest that competition of diacids for iron complexation plays a larger role in secondary organic particle formation and growth in solution than $I$ from the inorganic content only.

Mass Spectrometric Analysis of Soluble Reaction Products. As stated in the Introduction, the formation pathways for soluble and insoluble SOA are an active area of research in atmospheric chemistry. The UHPLC-UV chromatograms recorded at $\lambda=210 \mathrm{~nm}$ for the reactions of catechol in the presence of $\mathrm{Fe}$ (III) in the solution of AS (Rxn 6, 10, and 
11, Table 1) are shown in Figure 3, with catechol (red lines) corresponding to peak 1 and the control for reactions without

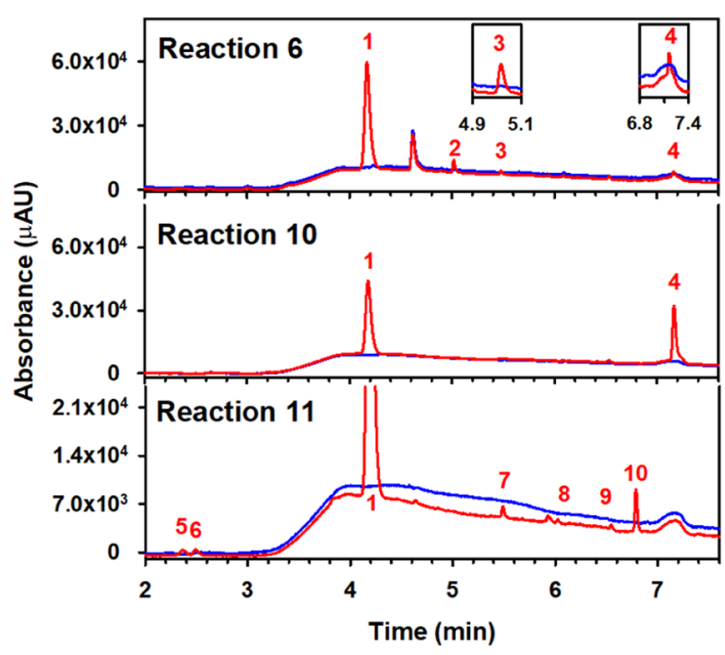

Figure 3. UHPLC-UV chromatogram $(\lambda=210 \mathrm{~nm})$ for (red lines) Rxn (top) 6, (center) 10, and (bottom) 11 after $24 \mathrm{~h}$ of reaction between catechol $\left(1 \times 10^{-3} \mathrm{M}\right), \mathrm{FeCl}_{3}\left(2 \times 10^{-3} \mathrm{M}\right)$ in AS solutions, as listed in Table 1 . The blue lines correspond to the respective control solutions without catechol. Except catechol (peak 1), all other labeled peaks correspond to products described in the text.

catechol (blue lines). These reactions were selected because their filtrate solutions shown in Figure 1 highlight the effect of dicarboxylic acids on the optical properties of the products. The focus of this part of the paper is entirely to investigate the labeled peaks 2 through 10 in the chromatograms, which were the only species appearing as products formed in the presence of catechol. The retention times, $\mathrm{m} / z$ values, and general elemental formula of labeled chromatographic peaks in Figure 3 are provided in Table 3 . Schemes S1 and S2 show mechanistic details and suggested structures of the molecules with the elemental formula in Table 3 . The $m / z^{-}$values in the negative ionization mode using formic acid as the modifier corresponded to anions formed after the loss of a proton from the neutral molecule. However, peak 3 did not display any anion and could only be identified in the positive ionization mode with the ammonium formate modifier by its $\mathrm{m} / \mathrm{z}^{+}$value from the $\mathrm{H}^{+}$and $\mathrm{NH}_{4}^{+}$adducts to the molecule.

The analysis of Figure 3 and Table 3 verifies that peak 1 corresponded to an anion at $m / z^{-} 109.10$ for catechol with the molecular formula $\mathrm{C}_{6} \mathrm{H}_{6} \mathrm{O}_{2}$. Furthermore, Figure 4 displays the extracted UV-visible spectra of the chromatographic peaks, which reinforced the reactant absorbing at $\lambda_{\max }=276 \mathrm{~nm}$. Peak 2 corresponded to an anion with $\mathrm{m} / \mathrm{z}^{-} 207.20$ and molecular formula $\mathrm{C}_{11} \mathrm{H}_{12} \mathrm{O}_{4}$, which could be tentatively assigned to either (a) 4-((1Z,3Z)-4,5-dihydroxypenta-1,3-dien-1-yl)benzene-1,2-diol or (b) 4-((1Z,3Z)-1,5-dihydroxypenta-1,3dien-1-yl)benzene-1,2-diol. Both isomers are formed during the oxidative cleavage of a ring with the loss of one carbon from a coupling product of catechol and pyrogallol molecules. Such assignments supported the absorption at $\lambda_{\max }=343 \mathrm{~nm}$ for peak 2 (Figure 4), possessing an extended chain of conjugated $\mathrm{C}=\mathrm{C}$ bonds. While peak 3 could not be detected as an anion, its $m / z^{+} 453.29$ and 470.32 for clusters with $1 \mathrm{H}^{+}$ and $1 \mathrm{NH}_{4}^{+}$, respectively, indicated a molecular formula of $\mathrm{C}_{18} \mathrm{H}_{12} \mathrm{O}_{14}$, which could be described by the structure of a polyhydroxylated quinone. For example, the structure of $2,2^{\prime \prime}, 3,3^{\prime \prime}, 4,4^{\prime \prime}, 5,5^{\prime}, 5^{\prime \prime}, 6,6^{\prime}, 6^{\prime \prime}$-dodecahydroxy- $\left[1,1^{\prime}: 4^{\prime}, 1^{\prime \prime}\right.$-terphenyl]-2', $3^{\prime}$-dione (or an isomer) including three aromatic rings explained the absorption extending to a $\lambda_{\max }=407 \mathrm{~nm}$ for peak 3. In addition, peak 4 present in the chromatogram of reaction 6 was confirmed to have ions at $m / z^{-} 212.18$, and at $\mathrm{m} / \mathrm{z}^{+} 214.20$ for the adduct with $1 \mathrm{H}^{+}$, indicating a molecular formula of $\mathrm{C}_{12} \mathrm{H}_{7} \mathrm{O}_{3} \mathrm{~N}$. The previous elemental formula was confirmed using $\left({ }^{15} \mathrm{NH}_{4}\right)_{2} \mathrm{SO}_{4}$ at $\mathrm{m} / z^{+} 215.20$ and HR-MS(+) (when using ${ }^{14} \mathrm{NH}_{4}^{+}$) detecting $\mathrm{m} / z^{+}$214.0501, which is only $1.1015 \mathrm{ppm}$ apart from $\mathrm{m} / z^{+} 214.0499$ for $\mathrm{C}_{12} \mathrm{H}_{8} \mathrm{O}_{3} \mathrm{~N}^{+}$. Considering the presence of a nitrogen atom in the molecule, and the strong absorption at $\lambda_{\max }=395 \mathrm{~nm}$ with a shoulder extending into the visible spectrum, the structure for a quinone imine such as $4^{\prime}$-imino- $\left[1,1^{\prime}\right.$-bi(cyclohexane) $]-1,1^{\prime}, 5,5^{\prime}$-tetraene-3,3',4-trione or an isomer is proposed to describe peak 4 .

The formation of a quinone imine from catechol should be mediated by $\mathrm{Fe}(\mathrm{III})$ catalysis, which generates $o$-quinone, and

Table 3. Retention Time (r.t.) for Chromatographic Peaks in Figure 3 with $m / z$ Values and Molecular Formula in the Negative and Positive Ion Modes ${ }^{a}$

\begin{tabular}{|c|c|c|c|c|c|c|}
\hline \multirow[b]{2}{*}{ peak \# } & \multirow[b]{2}{*}{ r.t. (min) } & \multicolumn{2}{|c|}{$m / z^{-}$} & \multicolumn{2}{|c|}{$m / z^{+}$} & \multirow[b]{2}{*}{ molecular formula } \\
\hline & & parent & fragment & parent & adduct & \\
\hline 1 & 4.17 & 109.10 & & & $\begin{array}{l}128.15 \\
\left(\mathrm{M}+\mathrm{NH}_{4}^{+}\right)\end{array}$ & $\mathrm{C}_{6} \mathrm{H}_{6} \mathrm{O}_{2}$ \\
\hline 2 & 5.02 & 207.20 & & & & $\mathrm{C}_{11} \mathrm{H}_{12} \mathrm{O}_{4}$ \\
\hline 3 & 5.48 & N.D. & & 453.29 & $\begin{array}{l}470.32 \\
\left(\mathrm{M}+\mathrm{NH}_{4}^{+}\right)\end{array}$ & $\mathrm{C}_{18} \mathrm{H}_{12} \mathrm{O}_{14}$ \\
\hline 4 & 7.16 & 212.18 & 173.19 & 214.20 & & $\mathrm{C}_{12} \mathrm{H}_{7} \mathrm{O}_{3} \mathrm{~N}$ \\
\hline 5 & 2.37 & 167.14 & 149.12 & & & $\mathrm{C}_{8} \mathrm{H}_{8} \mathrm{O}_{4}$ \\
\hline 6 & 2.49 & 167.10 & 123.09 & & & $\mathrm{C}_{7} \mathrm{H}_{4} \mathrm{O}_{5}$ \\
\hline 7 & 5.49 & 217.20 & & & $\begin{array}{l}471.48 \\
\left(2 \mathrm{M}+2 \mathrm{NH}_{4}^{+}-\mathrm{H}^{+}\right)\end{array}$ & $\mathrm{C}_{12} \mathrm{H}_{10} \mathrm{O}_{4}$ \\
\hline 8 & 6.03 & 315.25 & & & $\begin{array}{l}334.30 \\
\left(\mathrm{M}+\mathrm{NH}_{4}^{+}\right)\end{array}$ & $\mathrm{C}_{16} \mathrm{H}_{12} \mathrm{O}_{7}$ \\
\hline 9 & 6.54 & 249.20 & & 251.21 & & $\mathrm{C}_{12} \mathrm{H}_{10} \mathrm{O}_{6}$ \\
\hline 10 & 6.79 & 365.27 & & & $\begin{array}{l}384.31 \\
\left(\mathrm{M}+\mathrm{NH}_{4}^{+}\right)\end{array}$ & $\mathrm{C}_{16} \mathrm{H}_{14} \mathrm{O}_{10}$ \\
\hline
\end{tabular}

${ }^{a}$ See Schemes S1 and S2 for suggested structural formulas. N.D. = not detected. 


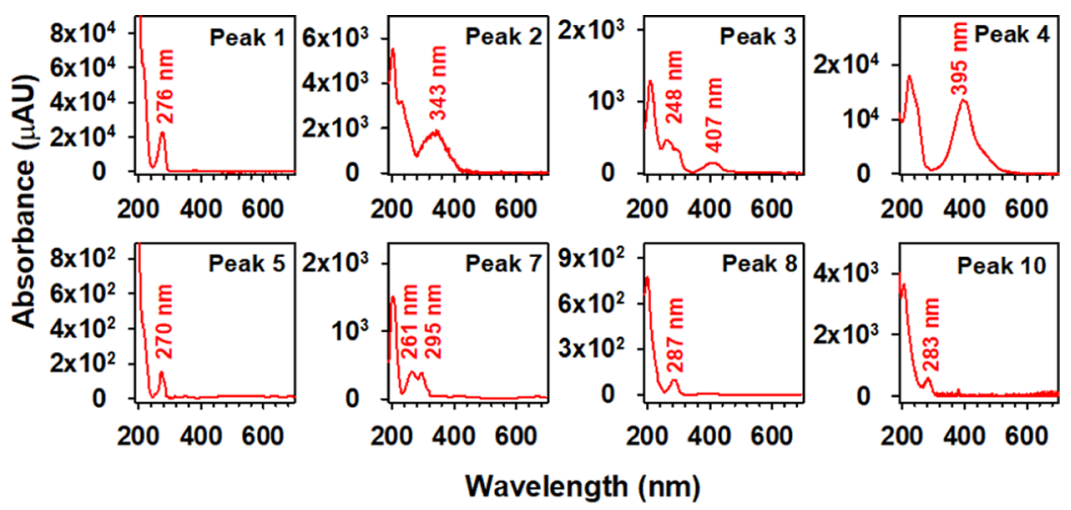

Figure 4. Extracted UV-visible spectra of peaks 1, 2, 3, 4, 5, 7, 8, and 10 in the chromatograms of Figure 3, where chromatograms are shown for reactions 6,10 , and 11 after $24 \mathrm{~h}$ of reaction between catechol $\left(1 \times 10^{-3} \mathrm{M}\right), \mathrm{FeCl}_{3}\left(2 \times 10^{-3} \mathrm{M}\right)$ in AS solutions, as listed in Table 1 .

in the presence of ammonia, produced the imine that undergoes a coupling reaction. The catalytic power of the catechol/o-quinone redox pair together with the complex equilibria for $\mathrm{Fe}$ (III) and $\mathrm{Fe}$ (II) ions with catechol and dicarboxylic acids should play a key role in the formation of the novel species proposed. Such organonitrogen molecule was not recognized in earlier studies but is now available for further evaluation in new laboratory studies and field sampling, where it can play a role as a reactive intermediate. The nitrogencontaining organic carbon (NOC) that corresponds to peak 4 described above belongs to the reductive NOC class that includes amines, imines, and imidazoles. In general, NOC is increasing in importance as a class of brown carbon in atmospheric organic aerosol. ${ }^{5,50,51}$ Particle phase formation of NOC is driven by ammonia uptake on newly formed SOA from the oxidation of $\alpha$-pinene and $m$-xylene $e^{52}$ and evaporation of glyoxal-ammonium sulfate droplets. ${ }^{53}$ Reactions with $\mathrm{NO}_{2}$ and $\mathrm{NO}_{3}$ lead to nitration of polycyclic aromatic hydrocarbons yielding nitrophenols, nitrocatechols, ${ }^{54-57}$ nitration of isoprene-derived epoxides during SOA formation, ${ }^{58}$ and nitro-heterocyclic compounds such as nitropyrrole. ${ }^{59}$ Hence, metal-catalyzed reactions driven by dissolved oxygen that lead to the formation of NOC in particles are potentially important pathways in systems containing ammonium and transition metals, which warrant further investigation.

The fact that peak 4 with $\lambda_{\max } \sim 400 \mathrm{~nm}$ is also registered in the chromatogram for Rxn 10 (Figure 3) indicated that GA influenced the oligomerization reaction in a similar manner as MA in Rxn 6. This strongly absorbing product in the near UV and visible spectrum (Figure 4) characterized the major features of the catechol/GA/SA reaction with iron (Figure S5a, Supporting Information). This feature was also present in Rxn 9 for the reaction of catechol/GA with iron in the absence of SA (Figure S5b, Supporting Information). The broad absorption feature in Figure S5c for the filtrate of the catechol/MA reaction with iron ( $\mathrm{Rxn} 6$ ) showed the existence of a peak with $\lambda \sim 400 \mathrm{~nm}$. These findings suggested that SA is not a key player for the formation of the species assigned to peak 4, which were in line with the DLS analysis described above. Hence, the absence of the species responsible for peak 4 in $\mathrm{Rxn} 11$ containing catechol/Mal/SA and iron suggested that Mal suppressed oligomerization reactions due to the formation of soluble and stable iron malonate complexes.

From the data continuously recorded by the photodiode array detector, we extracted the UV-visible spectra of chromatographic peaks $5,7,8$, and 10 , which are presented in Figure 4. However, the low abundance of the species corresponding to chromatographic peaks 6 and 9 prevented us from characterizing them in the UV-visible region. The welldefined electronic transitions for the absorption spectra of peaks $5,7,8$, and 10 are typical of $n \rightarrow \pi^{*}$ transitions but are still far from the visible range. Peak 5 in Figure 3 with $\mathrm{m} / \mathrm{z}^{-}$ 167.14 and absorption at $\lambda_{\max }=270 \mathrm{~nm}$ corresponded to a molecular formula $\mathrm{C}_{8} \mathrm{H}_{8} \mathrm{O}_{4}$, with a proposed structure of 2(3,4-dihydroxyphenyl)acetic acid (Scheme S2). This carboxylic acid species at $m / z^{-} 167.14$ with the same fragment loss of 18 amu was registered by ion chromatography mass spectrometry (IC-MS) at $27.65 \mathrm{~min}$. Peak 6, with $\mathrm{m} / \mathrm{z}^{-} 167.10$ and molecular formula $\mathrm{C}_{7} \mathrm{H}_{4} \mathrm{O}_{5}$, could undergo a $\beta$-ketocarboxylic acid decarboxylation loosing $44 \mathrm{amu}$ as explained, i.e., by a proposed structure of 4-hydroxy-5,6-dioxocyclohexa-1,3-dienecarboxylic acid. Both structures for peaks 5 and 6 arose after oxidative cleavage of coupling products.

Peak 7 (Figure 3) with $m / z^{-} 217.20$ for a molecular formula $\mathrm{C}_{12} \mathrm{H}_{10} \mathrm{O}_{4}$ and absorption maxima at $\lambda_{\text {max }, 1}=261 \mathrm{~nm}$ and $\lambda_{\text {max }, 2}$ $=295 \mathrm{~nm}$ was described by a coupling isomer of catechol such as $\left[1,1^{\prime}\right.$-biphenyl $]-3,3^{\prime}, 4,4^{\prime}$-tetraol. Peak 8 with $m / z^{-} 315.25$ was assigned to a molecular formula $\mathrm{C}_{16} \mathrm{H}_{12} \mathrm{O}_{7}$ for either isomer (Z)-4-oxo-2-( $3^{\prime}, 4,4^{\prime}, 5$-tetrahydroxy-[1,1' -biphenyl]-3yl)but-2-enoic acid or 2-hydroxy-3-( $3^{\prime}, 4,4^{\prime}, 5$-tetrahydroxy[1,1'-biphenyl]-3-yl)malealdehyde. Peak 9 at $m / z^{-} 249.20$ for $\mathrm{C}_{12} \mathrm{H}_{10} \mathrm{O}_{6}$ was well-described by the coupling structure of two pyrogallol molecules, $\left[1,1^{\prime}\right.$-biphenyl $]-3,3^{\prime}, 4,4^{\prime}, 5,5^{\prime}$-hexaol. Finally, peak 10 at $\mathrm{m} / \mathrm{z}^{-} 365.27$ for a molecule of $\mathrm{C}_{16} \mathrm{H}_{14} \mathrm{O}_{10}$ absorbing at $\lambda=283 \mathrm{~nm}$ could be described by an isomer with 1 open and 2 close rings: $2,2^{\prime}-\left(3,3^{\prime}, 4,4^{\prime}, 5,5^{\prime}\right.$-hexahydroxy[1,1'-biphenyl]-2,2' -diyl)bis(2-hydroxyacetaldehyde) or (E)-2$\left(3,3^{\prime}, 4,4^{\prime}, 5,5^{\prime}\right.$-hexahydroxy-[1,1'-biphenyl]-2-yl)-2,3,4-trihydroxybut-3-enal.

Figure S6 shows the IC chromatogram for Rxn 10, where the reactants glutarate $\left(m / z^{-} 131.11\right)$, succinate $\left(m / z^{-} 117.08\right)$, and hydrogen sulfate $\left(\mathrm{m} / \mathrm{z}^{-}\right.$97.07) all eluted between at 18.2 and $20.0 \mathrm{~min}$. The formation of $90 \mu \mathrm{M}$ oxalate product at $20.72 \mathrm{~min}$, only detected in the extracted ion chromatogram at $\mathrm{m} / \mathrm{z}^{-} 89.03$ (Figure S6), is typical for the deep oxidation of organic matter and has been observed before for catechol. ${ }^{54-56}$ Oxalic acid is a highly soluble organic species that could be considered an endpoint oxidation product in this system before the final conversion of catechol into formic acid and $\mathrm{CO}_{2}{ }^{60-63}$ In other words, although the ratio of the detected product to initial reactant $[$ oxalic acid $] /[\text { catechol }]_{0}<10 \%$, the detection of this product demonstrates that a complex chain of oxidation 
reactions must have occurred, which typically implied the presence of reactive dicarbonyls and ketocarboxylic acids intermediates. $^{61,62,64}$

In conclusion, our novel studies showed that the rate of ironcatalyzed polycatechol formation/aggregation in solution was significantly reduced in systems with high ionic strength $(I>1$ $m$ ) and in the presence of competing diacids with the oxygento-carbon molar ratio $(\mathrm{O}: \mathrm{C})$ greater than 1 . This reduction in the rate of the insoluble product formation allowed for the detection of soluble oligomers that were not previously observed in similar systems under lower ionic strength $(I \sim$ $0.01 \mathrm{M})$ or from VOC oxidation. ${ }^{64}$ Formation of colored organonitrogen oligomers in samples containing ammonium sulfate highlights a new pathway driven by iron chemistry that forms nitrogen-containing nucleophiles. In addition, the reactivity of aerosol systems with similar chemical compositions like those studied here could lead to liquid-solid phase separation and changes to mixing states and morphologies depending on the type of the diacid in the system. These changes to aerosol physical properties would aid in interpreting images collected from field and lab studies. ${ }^{29,30,65}$ While diacids of a wide range of $\mathrm{O}: \mathrm{C}$ ratio are often grouped together as a class of organics in atmospheric aerosols, our studies highlight that knowledge of their thermodynamic $\mathrm{p} K_{\mathrm{a}}$ values only, some of which are currently incorporated in atmospheric chemistry models, is not enough to fully understand their complexation and reactivity with transition metals. The knowledge of structural effects on the kinetics of these reactions provides invaluable information on the role of the diacids in changing chemical and physical properties of aerosols.

\section{ASSOCIATED CONTENT}

\section{S1 Supporting Information}

The Supporting Information is available free of charge at https://pubs.acs.org/doi/10.1021/acs.est.0c05678.

Detailed materials and methods, additional figures and tables, equilibrium constants for different reactions, and list of abbreviations (PDF)

\section{AUTHOR INFORMATION}

\section{Corresponding Authors}

Hind A. Al-Abadleh - Department of Chemistry and Biochemistry, Wilfrid Laurier University, Waterloo, Ontario N2L 3C5, Canada; 이이.org/0000-0002-9425-0646; Phone: (519)884-0710; Email: halabadleh@wlu.ca; Fax: (519)746-0677

Marcelo I. Guzman - Department of Chemistry, University of Kentucky, Lexington, Kentucky 40506, United States; (1) orcid.org/0000-0002-6730-7766; Phone: (859)3232892; Email: marcelo.guzman@uky.edu; Fax: (859)3239985

\section{Authors}

Md Sohel Rana - Department of Chemistry, University of Kentucky, Lexington, Kentucky 40506, United States

Wisam Mohammed - Department of Chemistry and Biochemistry, Wilfrid Laurier University, Waterloo, Ontario N2L 3C5, Canada

Complete contact information is available at: https://pubs.acs.org/10.1021/acs.est.0c05678

\section{Notes}

The authors declare no competing financial interest.

\section{ACKNOWLEDGMENTS}

H.A.A. acknowledges the partial funding from Laurier, NSERC, Canadian Foundation for Innovation, and the Fulbright Canada Research Chair in Atmospheric Chemistry, Air Quality and Climate Change program at the University of California Irvine. M.I.G. thanks the U.S.A. National Science Foundation for research funding under award 1903744. The authors thank professor Vladimir Kitaev (Laurier) for access to the DLS instrument and professor Allan Bertram for stimulating the discussions.

\section{REFERENCES}

(1) Zhang, R.; Khalizov, A.; Wang, L.; Hu, M.; Xu, W. Nucleation and growth of nanoparticles in the atmosphere. Chem. Rev. 2012, 112, 1957-2011.

(2) Pöschl, U. Atmospheric aerosols: Compostion, transformation, climate and health effects. Angew. Chem., Int. Ed. 2005, 44, 75207540.

(3) Farmer, D. K.; Cappa, C. D.; Kriedenweis, S. M. Atmospheric processes and their controlling influence on cloud condensation nuclei activity. Chem. Rev. 2015, 115, 4199-4217.

(4) Ziemann, P. J.; Atkinson, R. Kinetics, products, and mechanisms of secondary organic aerosol formation. Chem. Soc. Rev. 2012, 41, $6582-6605$

(5) Laskin, A.; Laskin, J.; Nizkorodov, S. A. Chemistry of atmospheric brown carbon. Chem. Rev. 2015, 115, 4335-4382.

(6) Al-Abadleh, H. A. A review on the bulk and surface chemistry of iron in atmospherically-relevant systems containing humic like substances. RSC Adv. 2015, 5, 45785-45811.

(7) Ito, A. Atmospheric processing of combustion aerosols as a source of bioavailable iron. Environ. Sci. Technol. Lett. 2015, 2, 70-75.

(8) Oakes, M.; Weber, R. J.; Lai, B.; Russell, A.; Ingall, E. D. Characterization of iron speciation in urban and rural single particles using XANES spectroscopy and micro $\mathrm{x}$-ray fluorescence measurements: Investigating the relationship between speciation and fractional iron solubility. Atmos. Chem. Phys. 2012, 12, 745-756.

(9) Ault, A. P.; Peters, T. M.; Sawvel, E. J.; Casuccio, G. S.; Willis, R. D.; Norris, G. A.; Grassian, V. H. Single-particle SEM-EDX analysis of iron-containing coarse particulate matter in an urban environment: Sources and distribution of iron within Cleveland, Ohio. Environ. Sci. Technol. 2012, 46, 4331-4339.

(10) Guasco, T. L.; Cuadra-Rodriguez, L. A.; Pedler, B. E.; Ault, A. P.; Collins, D. B.; Zhao, D.; Kim, M. J.; Ruppel, M. J.; Wilson, S. C.; Pomeroy, R. S.; Grassian, V. H.; Azam, F.; Bertram, T. H.; Prather, K. A. Transition metal associations with primary biological particles in sea spray aerosol generated in a wave channel. Environ. Sci. Technol. 2014, 48, 1324-1333.

(11) Li, W.; Shao, L.; Shi, Z.; Chen, J.; Yuan, Q.; Yan, C.; Zhang, X.; Wang, Y.; Sun, J.; Zhang, Y.; Shen, X.; Wang, Z.; Wang, W.; et al. Mixing state and hygroscopicity of dust and haze particles before leaving Asian continent. J. Geophys. Res. Atmos. 2014, 119, 10441059.

(12) Grgic, I. Metals in Aerosols. In Environmental Chemistry of Aerosols; Colbeck, I., Ed.; Blackwell Publishing Ltd.: Oxford, UK, 2008; pp 117-139.

(13) Winton, V. H. L.; Edwards, R.; Bowie, A. R.; Keywood, M. D.; Williams, A. G.; Chambers, S. D.; Selleck, P. W.; Desservettaz, M.; Mallet, M. D.; Paton-Walsh, C. Dry season aerosol iron solubility in tropical northern Australia. Atmos. Chem. Phys. 2016, 16, 1282912848 .

(14) Shi, Z. B.; Krom, M. D.; Jickells, T. D.; Bonneville, S.; Carslaw, K. S.; Mihalopoulos, N.; Baker, A. R.; Benning, L. G. Impacts on iron solubility in the mineral dust by processes in the source region and the atmosphere: A review. Aeolian Res. 2012, 5, 21-42. 
(15) Shi, Z.; Krom, M. D.; Bonneville, S.; Benning, L. G. Atmospheric processing outside clouds increases soluble iron in mineral dust. Environ. Sci. Technol. 2015, 49, 1472-1477.

(16) Link, N.; Removski, N.; Yun, J.; Fleming, L.; Nizkorodov, S. A.; Bertram, A. K.; Al-Abadleh, H. A. Dust-catalyzed oxidative polymerization of catechol under acidic conditions and its impacts on ice nucleation efficiency and optical properties. ACS Earth Space Chem. 2020, 4, 1127-1139.

(17) Grgić, I.; Dovzan, A.; Bercic, G.; Hudnik, V. The effect of atmospheric organic compounds on the Fe-catalyzed S(IV) autoxidation in aqueous solution. J. Atmos. Chem. 1998, 29, 315-337.

(18) Novič, M.; Grgic, I.; Poje, M.; Hudnik, V. Iron-catalyzed oxidation of S(IV) species by oxygen in aqueous solution: Influence of $\mathrm{pH}$ on the redox cycling of iron. Atmos. Environ. 1996, 30, 41914196.

(19) Huang, L.; Cochran, R. E.; Coddens, E. M.; Grassian, V. H. Formation of organosulfur compounds through transition metal ioncatalyzed aqueous phase reactions. Environ. Sci. Technol. Lett. 2018, 5, 315-321.

(20) Slikboer, S.; Grandy, L.; Blair, S. L.; Nizkorodov, S. A.; Smith, R. W.; Al-Abadleh, H. A. Formation of light absorbing soluble secondary organics and insoluble polymeric particles from the dark reaction of catechol and guaiacol with $\mathrm{Fe}(\mathrm{III})$. Environ. Sci. Technol. 2015, 49, 7793-7801.

(21) Tran, A.; William, G.; Younus, S.; Ali, N. N.; Blair, S. L.; Nizkorodov, S. A.; Al-Abadleh, H. A. Efficient formation of lightabsorbing polymeric nanoparticles from the reaction of soluble $\mathrm{Fe}(\mathrm{III})$ with C4 and C6 dicarboxylic acids. Environ. Sci. Technol. 2017, 51, 9700-9708.

(22) Al Nimer, A.; Rocha, L.; Rahman, M. A.; Nizkorodov, S. A.; AlAbadleh, H. A. Effect of oxalate and sulfate on iron-catalyzed secondary brown carbon formation. Environ. Sci. Technol. 2019, 53, 6708-6717.

(23) Shi, G. L.; Xu, J.; Peng, X.; Xiao, Z.; Chen, K.; Tian, Y.; Guan, X.; Feng, Y.; Yu, H.; Nenes, A.; Russell, A. $\mathrm{pH}$ of aerosols in a polluted atmosphere: Source contributions to highly acidic aerosol. Environ. Sci. Technol. 2017, 51, 4289-4296.

(24) Nguyen, T. K. V.; Zhang, Q.; Jimenez, J. L.; Pike, M.; Carlton, A. G. Liquid water: Ubiquitous contributor to aerosol mass. Environ. Sci. Technol. Lett. 2016, 3, 257-263.

(25) Herrmann, H.; Schaefer, T.; Tilgner, A.; Styler, S. A.; Weller, C.; Teich, M.; Otto, T. Tropospheric aqueous-phase chemistry: Kinetics, mechanisms, and its coupling to a changing gas phase. Chem. Rev. 2015, 115, 4259-4334.

(26) Finlayson-Pitts, B. J.; Pitts, J. N., Jr. Chemistry of the Upper and Lower Atmosphere; Academic Press: New York, 2000.

(27) Seinfeld, J. H.; Pandis, S. N. Atmospheric Chemistry and Physics: From Air Pollution to Climate Change; Wiley: New York, 2006.

(28) You, Y.; Smith, M. L.; Song, M.; Martin, S. T.; Bertram, A. K. Liquid-liquid phase separation in atmospherically relevant particles consisting of organic species and inorganic salts. Int. Rev. Phys. Chem. 2014, 33, 43-77.

(29) Freedman, M. A. Phase separation in organic aerosol. Chem. Soc. Rev. 2017, 46, 7694-7705.

(30) Song, M.; Marcolli, C.; Krieger, U. K.; Lienhard, D. M.; Peter, T. Morphologies of mixed organic/inorganic/aqueous aerosol droplets. Faraday Discuss. 2013, 165, 289-316.

(31) Riemer, N.; Ault, A. P.; West, M.; Craig, R. L.; Curtis, J. H. Aerosol mixing state: Measurements, modeling, and impacts. Rev. Geophys. 2019, 57, 187-249.

(32) Kuwata, M.; Martin, S. T. Phase of atmospheric secondary organic material affects its reactivity. Proc. Natl. Acad. Sci. U.S.A. 2012, 109, 17354-17359.

(33) Shiraiwa, M.; Ammann, M.; Koop, T.; Pöschl, U. Gas uptake and chemical aging of semisolid organic aerosol particles. Proc. Natl. Acad. Sci. U.S.A. 2011, 108, 11003-11008.

(34) Alpert, P. A.; Arroyo-Abad, U.; Dou, J.; Krieger, U. K.; Steimer, S. S.; Forster, J.-D.; Ditas, F.; Pohlker, C.; Rossignol, S.; Passananti, M.; Perrier, S.; George, C.; Shiraiwa, M.; Berkemeier, T.; Watts, B.;
Ammann, M. Visualizing reaction and diffusion in xanthan gum aerosol particles exposed to ozone. Phys. Chem. Chem Phys. 2019, 21, 20613-20627.

(35) Craig, R. L.; Nandy, L.; Axson, J. L.; Dutcher, C. S.; Ault, A. P. Spectroscopic determination of aerosol $\mathrm{pH}$ from acid-base equilibria in inorganic, organic, and mixed systems. J. Phys. Chem. A 2017, 121, $5690-5699$.

(36) Kreidenweis, S. M.; Koehler, K.; DeMott, P. J.; Prenni, A. J.; Carrico, C.; Ervens, B. Water activity and activation diameters from hygroscopicity data - part I: Theory and application to inorganic salts. Atmos. Chem. Phys. 2005, 5, 1357-1370.

(37) Kundu, S.; Kawamura, K.; Andreae, T. W.; Hoffer, A.; Andreae, M. O. Molecular distributions of dicarboxylic acids, ketocarboxylic acids and $\alpha$-dicarbonyls in biomass burning aerosols: Implications for photochemical production and degradation in smoke layers. Atmos. Chem. Phys. 2010, 10, 2209-2225.

(38) Okochi, H.; Brimblecombe, P. Potential trace metal-organic complexation in the atmosphere. Sci. World J. 2002, 2, 767-786.

(39) Visual MINTEQ ver. 3.1. https://vminteq.lwr.kth.se.

(40) Marcolli, C.; Luo, B.; Peter, T. Mixing of the organic aerosol fractions: Liquids as the thermodynamically stable phases. J. Phys. Chem. A 2004, 108, 2216-2224.

(41) Xia, S.-S.; Eugene, A. J.; Guzman, M. I. Cross photoreaction of glyoxylic and pyruvic acids in model aqueous aerosol. J. Phys. Chem. A 2018, 122, 6457-6466.

(42) Chen, Q.; Farmer, D. K.; Schneider, J.; Zorn, S. R.; Heald, C. L.; Karl, T. G.; Guenther, A.; Allan, J. D.; Robinson, N.; Coe, H.; Kimmel, J. R.; Pauliquevis, T.; Borrmann, S.; Poschl, U.; Andreae, M. O.; Artaxo, P.; Jimenez, J. L.; Martin, S. T. Mass spectral characterization of submicron biogenic organic particles in the amazon basin. Geophys. Res. Lett. 2009, 36, No. L20806.

(43) Jimenez, J. L.; Canagaratna, M. R.; Donahue, N. M.; Prevot, A. S. H.; Zhang, Q.; Kroll, J. H.; DeCarlo, P. F.; Allan, J. D.; Coe, H.; Ng, N. L.; Aiken, A. C.; Docherty, K. S.; Ulbrich, I. M.; Grieshop, A. P.; Robinson, A. L.; Duplissy, J.; Smith, J. D.; Wilson, K. R.; Lanz, V. A.; Hueglin, C.; Sun, Y. L.; Tian, J.; Laaksonen, A.; Raatikainen, T.; Rautiainen, J.; Vaattovaara, P.; Ehn, M.; Kulmala, M.; Tomlinson, J. M.; Collins, D. R.; Cubison, M. J.; Dunlea, E. J.; Huffman, J. A.; Onasch, T. B.; Alfarra, M. R.; Williams, P. I.; Bower, K.; Kondo, Y.; Schneider, J.; Drewnick, F.; Borrmann, S.; Weimer, S.; Demerjian, K.; Salcedo, D.; Cottrell, L.; Griffin, R.; Takami, A.; Miyoshi, T.; Hatakeyama, S.; Shimono, A.; Sun, J. Y.; Zhang, Y. M.; Dzepina, K.; Kimmel, J.; Sueper, D.; Jayne, J.; Herndon, S. C.; Trimborn, A. M.; Williams, L. R.; Wood, E. C.; Middlebrook, A. M.; Kolb, C. E.; Baltensperger, U.; Worsnop, D. R. Evolution of organic aerosols in the atmosphere. Science 2009, 326, 1525-1529.

(44) Ng, N. L.; Canagaratna, M. R.; Zhang, Q.; Jimenez, J. L.; Tian, J.; Ulbrich, I. M.; Kroll, J. H.; Docherty, K. S.; Chhabra, P. S.; Bahreini, R.; Murphy, S. M.; Seinfeld, J. H.; Hildebrandt, L.; Donahue, N. M.; DeCarlo, P. F.; Lanz, V. A.; Prevot, A. S. H.; Dinar, E.; Rudich, Y.; Worsnop, D. R. Organic aerosol components observed in northern hemispheric datasets from aerosol mass spectrometry. Atmos. Chem. Phys. 2010, 10, 4625-4641.

(45) Bertram, A. K.; Martin, S. T.; Hanna, S. J.; Smith, M. L.; Bodsworth, A.; Chen, Q.; Kuwata, M.; Liu, A.; You, Y.; Zorn, S. R. Predicting the relative humidities of liquid-liquid phase separation, efflorescence, and deliquescence of mixed particles of ammonium sulfate, organic material, and water using the organic-to-sulfate mass ratio of the particle and the oxygen-to-carbon elemental ratio of the organic component. Atmos. Chem. Phys. 2011, 11, 10995-11006.

(46) Perron, N. R.; Brumaghim, J. L. A review of the antioxidant mechanisms of polyphenol compounds related to iron binding. Cell Biochem. Biophys. 2009, 53, 75-100.

(47) Edwards, H. G. M.; Russell, N. C. Vibrational spectroscopic study of iron(II) and iron(III) oxalates. J. Mol. Struct. 1998, 443, 223-231.

(48) Khoe, G. H.; Robins, R. G. The complexation of iron(III) with sulphate, phosphate, or arsenate ion in sodium nitrate medium at 25 ${ }^{\circ}$ C. J. Chem. Soc., Dalton Trans. 1988, 8, 2015-2021. 
(49) Lovell, P. A.; Young, R. J. Introduction to Polymers; CRC Press: Boca Raton, FL, 2011.

(50) Liu, P.; Li, Y. J.; Wang, Y.; Bateman, A. P.; Zhang, Y.; Gong, Z.; Bertram, A. K.; Martin, S. T. Highly viscous states affect the browning of atmospheric organic particulate matter. ACS Cent. Sci. 2018, 4, 207-215.

(51) Moise, T.; Flores, J. M.; Rudich, Y. Optical properties of secondary organic aerosols and their changes by chemical processes. Chem. Rev. 2015, 115, 4400-4439.

(52) Liu, Y.; Liggio, J.; Staebler, R.; Li, S.-M. Reactive uptake of ammonia to secondary organic aerosols: Kinetics of organonitrogen formation. Atmos. Chem. Phys. 2015, 15, 13569-13584.

(53) Lee, A. K. Y.; Zhao, R.; Li, R.; Liggio, J.; Li, S.-M.; Abbatt, J. P. D. Formation of light absorbing organo-nitrogen species from evaporation of droplets containing glyoxal and ammonium sulfate. Environ. Sci. Technol. 2013, 47, 12819-12826.

(54) Jacobson, M. Z. Isolating nitrated and aromatic aerosols and nitrated aromatic gases as sources of ultraviolet light absorption. J. Geophys. Res.: Atmos. 1999, 104, 3527-3542.

(55) Pitts, J. N.; Van Cauwenberghe, K. A.; Grosjean, D.; Schmid, J. P.; Fitz, D. R.; Belser, W. L.; Knudson, G.; Hynds, P. M. Atmospheric reactions of polycyclic aromatic hydrocarbons: Facile formation of mutagenic nitro derivatives. Science 1978, 202, 515-519.

(56) Liu, P. F.; Abdelmalki, N.; Hung, H. M.; Wang, Y.; Brune, W. H.; Martin, S. T. Ultraviolet and visible complex refractive indices of secondary organic material produced by photooxidation of the aromatic compounds toluene and $m$-xylene. Atmos. Chem. Phys. 2015, $15,1435-1446$

(57) Vidović, K.; Lašič Jurković, D. L.; Šala, M.; Kroflič, A.; Grgić, I. Nighttime aqueous-phase formation of nitrocatechols in the atmospheric condensed phase. Environ. Sci. Technol. 2018, 52, 9722-9730.

(58) Darer, A. I.; Cole-Filipiak, N. C.; O’Connor, A. E.; Elrod, M. J. Formation and stability of atmospherically relevant isoprene-derived organosulfates and organonitrates. Environ. Sci. Technol. 2011, 45, 1895-1902.

(59) Jiang, H.; Frie, A. L.; Lavi, A.; Chen, J. Y.; Zhang, H.; Bahreini, R.; Lin, Y.-H. Brown carbon formation from nighttime chemistry of unsaturated heterocyclic volatile organic compounds. Environ. Sci. Technol. Lett. 2019, 6, 184-190.

(60) Eugene, A. J.; Xia, S.-S.; Guzman, M. I. Aqueous photochemistry of glyoxylic acid. J. Phys. Chem. A 2016, 120, 3817-3826.

(61) Pillar, E. A.; Camm, R. C.; Guzman, M. I. Catechol oxidation by ozone and hydroxyl radicals at the air-water interface. Environ. Sci. Technol. 2014, 48, 14352-14360.

(62) Pillar, E. A.; Guzman, M. I. Oxidation of substituted catechols at the air-water interface: Production of carboxylic acids, quinones, and polyphenols. Environ. Sci. Technol. 2017, 51, 4951-4959.

(63) Pillar, E. A.; Zhou, R.; Guzman, M. I. Heterogeneous oxidation of catechol. J. Phys. Chem. A 2015, 119, 10349-10359.

(64) Tolocka, M. P.; Jang, M.; Ginter, J. M.; Cox, F. J.; Kamens, R. M.; Johnston, M. V. Formation of oligomers in secondary organic aerosol. Environ. Sci. Technol. 2004, 38, 1428-1434.

(65) Koop, T.; Bookhold, J.; Shiraiwa, M.; Pöschl, U. Glass transition and phase state of organic compounds: Dependency on molecular properties and implications for secondary organic erosols in the atmosphere. Phys. Chem. Chem Phys. 2011, 13, 19238-19255. 